\title{
EXPERIÊNCIAS NA LOCALIZAÇÃO DE ARTE E TRILHA DE UM GAME SOB TEMÁTICA ORIENTAL E NA CONSTRUÇÃO E TRADUÇÃO DE UM STORYTELLING
}

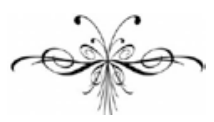

JORGE LUÍs ROCHA ${ }^{1}$

\begin{abstract}
Resumo: Neste ensaio, abordaremos duas experiências de produção e desenvolvimento de games pela Dumativa Estúdio de Criação, um estúdio independente situado na cidade do Rio de Janeiro. Ambos os projetos foram realizados durante os primeiros meses de funcionamento do estúdio, entre o final de 2011 e o primeiro semestre de 2012. O primeiro é um jogo 2D no estilo side-scrolling com temática visual, sonora e paratextual chinesa, voltado para um público majoritariamente de língua inglesa. $\mathrm{O}$ segundo projeto consiste em um storytelling game para PC baseado em narrativa por meio de leitura, em língua inglesa, cuja jogabilidade é centralizada em escolhas e consequências dentro de um enredo adaptável que se modifica segundo as opções e experiências de leitura do jogador. Focando as etapas de produção que dizem respeito à tradução e localização, nosso objetivo é demonstrar sua importância para a composição do produto final. Além disso, pretende-se indicar os caminhos da equipe de criação ao definir metodologias e estratégias nas fases de game design. Também serão tratadas questões relativas ao construir e aprimorar um estúdio independente de games, assim como à formação de uma equipe capaz de realizar as atividades de desenvolvimento de games com nível de excelência de mercado.
\end{abstract}

Palavras-chave: Localização. Tradução. Game design. Metodologia de produção.

\begin{abstract}
In this essay we discuss two game production and development experiences at Dumativa, an independent creation studio located in Rio de Janeiro. Both projects were undertaken during the studio's first months of operation, between late 2011 and the first half of 2012. The first project is a 2D side-scrolling game with a visual, sound and paratextual Chinese theme whose target group was predominantly English-speaking. The second project consists of a storytelling game for PC, also in English, whose gameplay is centered on choices and consequences within an adaptive storyline that changes according to the options and reading experiences of the players. Our goal in this essay is to show the importance of translation and localization to the final product. The paths of the creative team in defining methodologies and strategies during the game design process is also shown. Issues related to building and developing an independent game studio, as well as a team capable of developing games of a high level of excellence, are also covered.
\end{abstract}

Keywords: Localization. Translation. Game design. Production methodology.

\footnotetext{
${ }^{1}$ Jorge Luís Rocha é mestrando do Programa de Pós Graduação em Letras Neolatinas, na área de Espanhol - Língua Estrangeira, da Universidade Federal do Rio de Janeiro (UFRJ). Atua profissionalmente na Dumativa Estúdio de Criação (RJ) como escritor, tradutor e coordenador de projetos, além de atuar como docente de língua portuguesa, língua espanhola e de produção textual nos níveis fundamental e médio. Graduou-se em Letras Português/Espanhol pela UFRJ tendo integrado grupos de pesquisa nas áreas de Estudos da Tradução e Prosódia de Língua Espanhola e Portuguesa. Atualmente integra, como pesquisador, o grupo de pesquisa "Leitura, discurso e comunidade na formação e na atuação de professores de Espanhol Língua Estrangeira", além de realizar pesquisas sobre Games e Educação, Narrativa e Imersão em Games e Tradução.
} 


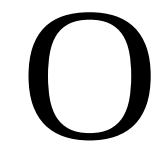

mercado de desenvolvimento de games vive atualmente uma fase de multiplicação de consumidores, assim como de crescimento das empresas desenvolvedoras. O despontar de algumas economias, como a do Brasil, criou novos nichos de consumo de jogos, o que promoveu o surgimento de diversos estúdios independentes no país - seja para produzirem seus próprios jogos ou para prestarem serviço às grandes empresas internacionais. Porém não são todos os que crescem e se tornam autossuficientes; as dificuldades de manutenção e de investimento de pequenos e médios estúdios independentes são inúmeras, o que pode afugentar profissionais desse ramo de trabalho. Desse modo, contratar profissionais para a produção de games não apenas gabaritados em suas áreas, mas também experientes e polivalentes, passa a ser bastante custoso, o que é incompatível economicamente para os pequenos estúdios indie.

Há um claro desafio quando um empresário ou um grupo de desenvolvedores decide abrir um estúdio, algo que ainda pode ser considerado um empreendimento pioneiro em algumas regiões do Brasil, mesmo com os avanços da área nos últimos anos. É preciso, muitas das vezes, elaborar seus métodos do zero, pensar estratégias adaptáveis a diferentes realidades, dialogar com os demais estúdios, trocar experiências, construir um modo próprio de trabalho. Em um mercado nacional com empresas de games de natureza e dimensão diversificadas, nem sempre um mesmo sistema cumpre com as necessidades e metas de todas elas.

É assim que a Dumativa Estúdio de Criação, uma desenvolvedora carioca de games, música e literatura, desde sua criação, busca elaborar métodos próprios que dinamizem seu processo criativo e, ao mesmo tempo, sejam economicamente viáveis. Tentando cada vez mais aprimorar as áreas envolvidas no desenvolvimento de nossos games, construímos soluções, prioridades e metodologias, revendo as que não funcionam e adotando as que dão certo. Adiante trataremos de duas experiências na área de tradução/localização em projetos de jogos desenvolvidos em nosso primeiro ano de existência.

\section{O que é a Dumativa}

Em outubro de 2011, a Dumativa Estúdio de Criação foi inaugurada oficialmente no Centro do Rio de Janeiro, tendo como foco a produção de games, música e literatura. Sua equipe é composta de 13 profissionais divididos entre as áreas de Programação, Design, Letras, Música e Gestão. O estúdio tem como objetivo principal a criação de obras autorais, tanto artísticas como de entretenimento, porém ao mesmo tempo visando a projetos mais amplos que atendam à divulgação da produção artística e à colaboração com outros estúdios independentes, além da prestação de serviços diversos a empresas e pessoas físicas. Desse modo, desde o princípio deu-se grande atenção à formação das equipes e dos métodos de trabalho para cada área, levando em conta as particularidades dos produtos desenvolvidos - até então consistindo basicamente de produção literária e musical, principalmente voltados a games.

No decorrer do primeiro ano de existência do estúdio, as principais áreas de produção já haviam dado grandes passos quanto à construção e dinamização de métodos. Entretanto, algumas atividades passaram por maiores dificuldades, uma delas o processo de tradução e localização dos produtos autorais. Observando as 
experiências de outros estúdios brasileiros de games, por meio de contatos com seus gestores e/ou integrantes, notamos dificuldades parecidas com a nossa na área de tradução, e soluções diferenciadas. Há estúdios que decidem terceirizar o processo de tradução e de localização - sobretudo o segundo, seguindo a lógica assumida por diversos estúdios independentes internacionais - e também há aqueles que concentram essas atividades internamente, porque já possuem profissionais qualificados para tal ou porque optaram por contratar pessoal com essa capacidade.

Levando em consideração que a Dumativa possui uma filosofia de gerir internamente soluções diversas para o desenvolvimento de seus produtos, ao mesmo tempo criando formas e estratégias de realizar suas atividades, decidimos terceirizar a tradução e a localização o mínimo possível, forçando-nos a elaborar um sistema próprio. Tal decisão, naturalmente, mostrou-se um grande desafio para um estúdio independente.

\section{O atual cenário carioca do mercado de games}

Um dos grandes obstáculos de estúdios de games no Rio de Janeiro é a carência de uma rede extensa de desenvolvedores na cidade, ainda que essa seja uma localidade muito favorável para a atividade, sobretudo pelo mercado consumidor local e pela boa disponibilidade de profissionais qualificados. O cenário brasileiro apresenta-se mais e mais favorável para estúdios independentes, com uma demanda consumidora crescente e mais frequentes incentivos, como a inclusão da produção de games na Lei Rouanet ${ }^{2}$ em 2011. Além disso, o número de desenvolvedores independentes no país também é relevante. Na “Global Game Jam 2013”, evento mundial de criação de games indies, ${ }^{3}$ o Brasil ficou em segundo lugar em número de sedes cadastradas, ficando atrás apenas do Egito. ${ }^{4}$

Mesmo assim, não houve um aumento relevante no número de estúdios no Rio de Janeiro - diferentemente de outros locais, como São Paulo, com estúdios bem desenvolvidos, como a "MiniBoss", e a região sul do Brasil, com a gaúcha "Swordtales”, primeira beneficiária da Lei Rouanet na área de games, responsável pelo aguardado Toren. Enquanto isso, a "Critical Studio", considerado um dos mais relevantes estúdios da cidade e do país - um dos produtores do bem sucedido Dungeonland -, surpreendeu ao fechar seu escritório no final de 2013.

Esse isolamento dos poucos desenvolvedores do Rio de Janeiro dificulta as atividades de estúdios independentes mais "jovens", pois a ausência de um campo de trocas e de inter-relação desacelera o estabelecimento de sistemas, métodos e estratégias para a criação de games. Levando em consideração que estúdios independentes locais em geral não representam concorrência, e sim colaboração mútua, a inexistência dessa rede na cidade é muito lamentada. Atualmente, boa parte dos es-

\footnotetext{
${ }^{2}$ A Lei Rouanet, vigente desde 1991, é um dispositivo governamental de incentivo à cultura que permite que pessoas físicas ou jurídicas invistam em projetos culturais, podendo deduzir grande parte do valor investido do Imposto de Renda. Em 2011 uma portaria incluiu jogos digitais na categoria de “projetos culturais”, sendo contemplados pela lei de incentivo, conforme noticiou no mesmo ano a revista EXAME.

${ }^{3}$ http://globalgamejam.org/

${ }^{4}$ http://2013.globalgamejam.org/status

${ }^{5}$ http://blog.studiominiboss.com/

${ }^{6}$ http://www.toren-game.com/blog/2011/09/swordtales-apresenta-toren/?lang=pt

${ }^{7}$ http://criticalstudio.com.br/anunciando-o-fechamento-da-critical/\#more-148
} 
túdios cariocas é voltada para a execução de determinadas etapas do processo de desenvolvimento, funcionando como prestadoras de serviço para estúdios maiores ou para empresas de setores diversos que necessitam de serviços visuais de animação.

Outro ponto negativo dessa escassez reflete-se na relação entre estúdios e investidores locais. Em decorrência da falta de grandes estúdios no Rio de Janeiro, é maior a dificuldade em demonstrar a investidores que o mercado de games pode ser bastante rentável, levando-os em grande parte a optar por capitalizar áreas que já possuam maior tradição na cidade. Sendo reduzido o número de investimentos externos e de patrocínios aos nossos produtos autorais, a autossuficiência e a autogestão no desenvolvimento de jogos foram encaradas como uma necessidade - levando em conta suas complicações, como a necessidade de aumentar o contingente de profissionais das equipes e aprimorar suas habilidades, evitando ao máximo a terceirização de tarefas, mas salvando seus consideráveis pontos positivos, como a busca constante de métodos próprios e pioneiros para a solução de problemas.

\section{Gestão interna e autossuficiente de tradução e localização}

Seguindo a estratégia de internalizar ao máximo as atividades de desenvolvimento de produtos, a maior preocupação da área de produção literária desde o início esteve na área de tradução e localização, já que a equipe apenas contava com um tradutor. Devido a isso, houve um número considerável de terceirizações de produção neste setor específico, além de questões e dilemas diversos durante o desenvolvimento de alguns de nossos produtos. A partir desta necessidade, procuramos cada vez mais buscar soluções práticas para lidar internamente com a tradução/localização, esbarrando em algumas limitações, mas alcançando passos importantes. A seguir, trataremos dos casos de tradução em dois de nossos produtos desenvolvidos em 2013 - um game side-scrolling ${ }^{8}$ 2D e um storytelling ${ }^{9}$.

\section{O primeiro caso de localização: Dragon Festival}

Um dos primeiros produtos desenvolvidos pela Dumativa, no final de 2013, foi o jogo Dragon Festival, um jogo em 2D para as plataformas móveis iPhone e iPad. Esse se constituiu no primeiro desafio de formação e consolidação de equipes e de estratégias de trabalho, sobretudo para as áreas de programação, design, trilha e sonorização. O desenvolvimento de Dragon Festival foi fundamental para integrar os profissionais das diversas áreas, que antes de 2012 ainda não haviam tido a experiência complexa de realizar coletivamente a produção de um game em estúdio.

Porém, o ponto-chave desse jogo foi impulsionar o estabelecimento dos primeiros métodos de tomada de decisão e de planejamento, estando aí incluídas as decisões a respeito de localização. Ainda que todos os profissionais da equipe tivessem cada um considerável experiência prévia em sua área, a localização era o que

\footnotetext{
${ }^{8}$ Side-scrolling é a definição que geralmente se dá a jogos cuja visão do jogador se faz lateralmente à ação, além de que os personagens virtualmente se deslocam de um lado para o outro da tela.

${ }^{9}$ Storytelling é a categoria de jogos nos quais a história assume um papel mais importante do que a própria ação.
} 
havia de mais abstrato na mente de todos. Essa relativa falta de experiência em localização fez com que esse tenha sido um dos últimos pontos a serem discutidos no processo de game design ${ }^{10}$. Porém, à medida que as reuniões de planejamento aconteciam, seu impacto tornou-se nítido a toda a equipe, o que foi crucial para que nos projetos seguintes a localização passasse a ser discutida logo no início do projeto.

\section{A China dos orientais - e também dos ocidentais}

A proposta temática de Dragon Festival foi voltada à antiga China, à sua cultura e sua arquitetura. O personagem principal do jogo é um dragão chinês, que em uma mecânica simples de fase, bastante semelhante a de outros side-scrollings, como o JetPack Joyride, da australiana Halfbrick Studios ${ }^{11}$, deve "voar" pela tela, desviando de obstáculos como postes chineses, foguetes e balões, ao mesmo tempo em que consome biscoitos espalhados pelo caminho.

A primeira discussão sobre a localização tratou dos elementos visuais, definindo-os por meio de pesquisas e referências gráficas à cultura chinesa. De diversas imagens de dragões clássicos surgiu o conceito do personagem principal, que ao longo do game pode trocar de cores - entre o verde, o azul e o vermelho - para absorver a energia dos itens de obstáculo. A escolha das três cores se deu não só pelo fato de serem as três cores básicas, mas também por serem representações de elementos básicos como a terra, a água e o fogo, em decorrência de pesquisas sobre a relação entre cores e os elementos da cultura chinesa.

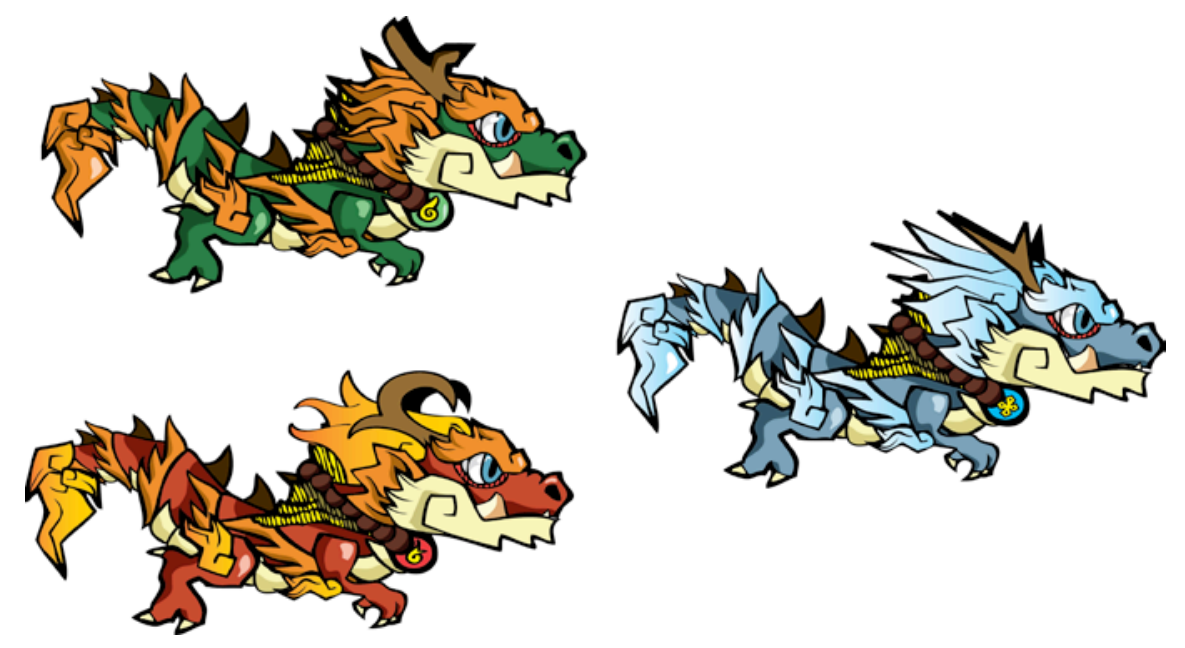

Figura 1. As três cores do Dragão

Os conceitos de obstáculos e cenários também foram construídos por meio de pesquisas extensas na área de arte. Porém no decorrer do detalhamento de arte uma questão crucial de localização veio à tona: se o jogo seria localizado para uma visão chinesa de cultura ou em uma visão que o público anglófono e norteamericano faz da cultura chinesa, já que se havia decidido que a língua utilizada

\footnotetext{
10 Trata-se do processo de criação dos argumentos e conceitos básicos de um jogo; ou seja, a definição do que o jogo é, em todos os seus aspectos, dos estéticos ao seu funcionamento.

${ }^{11}$ http://halfbrick.com/
} 
prioritariamente seria o inglês americano. Era mais um passo para a consideração do grau de importância do planejamento de localização para o projeto completo.
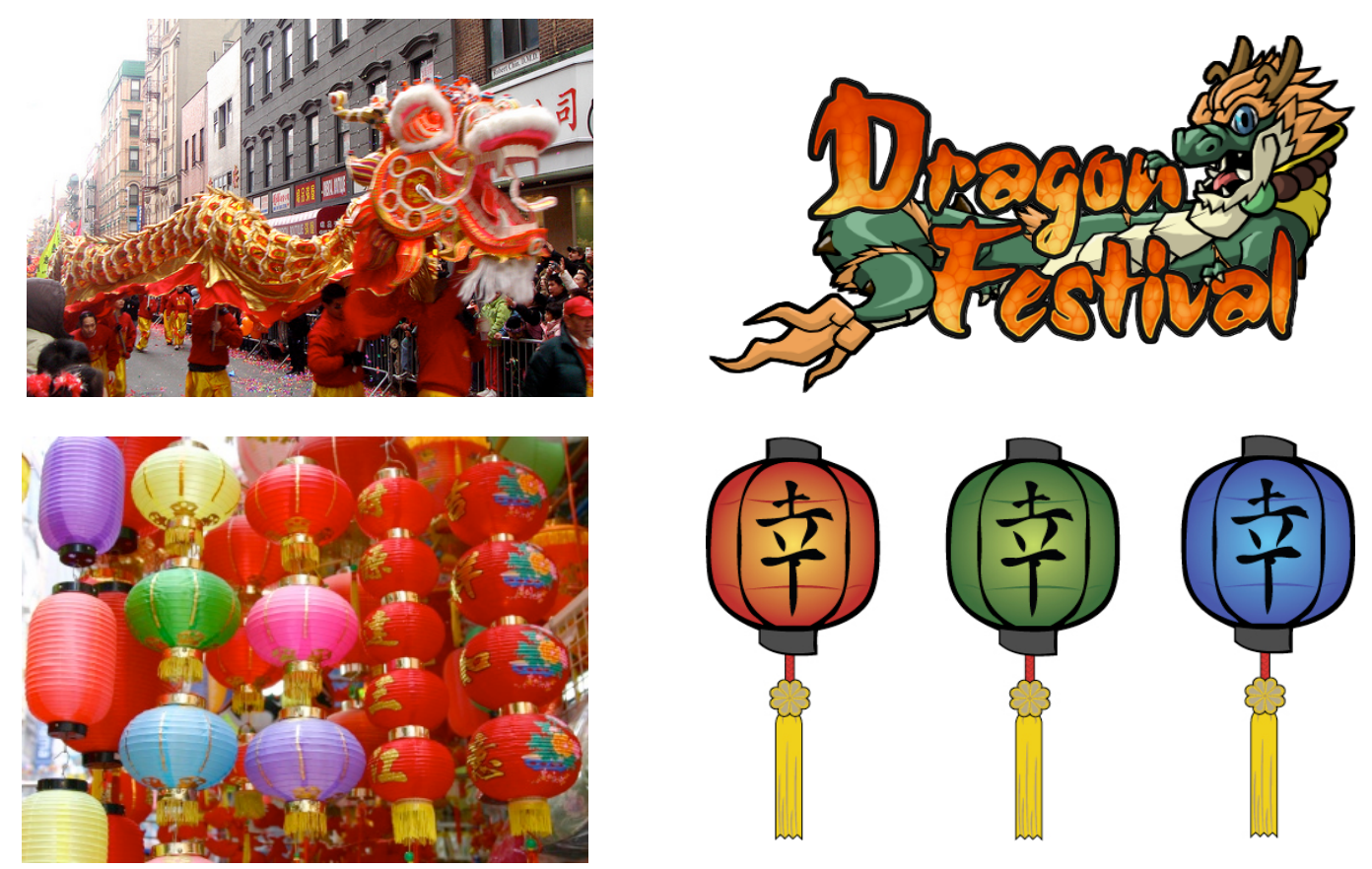

Figura 2. Representações da cultura chinesa na primeira versão de logo e elementos gráficos do jogo

Após a decisão de que o jogo seria localizado para o público anglófono norte-americano, porém evitando qualquer estereótipo de China veiculado por mídias ocidentais, passou-se à discussão sobre trilha e sonorização. O processo de pesquisa e referenciação ocorreu de modo similar ao da etapa de arte, resultando em efeitos sonoros e trilhas com características de harmonia e instrumentação tradicionais de músicas folclóricas chinesas, misturados a detalhes de timbres marcadamente ocidentais.

A partir disso, as discussões deram lugar à construção do paratexto do dragão e de seu universo dentro da cultura chinesa. Para o nome do personagem foi escolhido "Shen", pelas referências culturais a Shenlong, controlador dos céus e dos ventos, como também pelo significado da palavra, que é o de "espírito”. Essa escolha, assim como as dos demais elementos paratextuais, buscou centrar a temática textual em um aspecto mais tradicional, buscando significação dentro da cultura chinesa.

Com o desenvolvimento do jogo já em estágio avançado, como testagem da localização, jovens de descendência chinesa foram convidados para testar sua jogabilidade. O feedback foi positivo quanto à localização dos temas e dos elementos, tendo sido ressaltada a ausência de estereótipos, o que resultou em mais um estímulo relevante para o estabelecimento de uma etapa cuidadosa de localização no início de todos os projetos do estúdio. 


\section{Trabalhando com a língua anglo-americana}

Ao trabalhar com a língua inglesa, havia o grande problema em não contarmos com um tradutor do par Português-Inglês interno, o que nos obrigou a pensar em soluções alternativas à terceirização do serviço de tradução e revisão do conteúdo textual. Para dinamizar o processo e reduzir custos excedentes, utilizamos os profissionais internos de maior nível de proficiência em língua inglesa para a produção de elementos textuais básicos, como os textos de menus, linguagem verbal in game, etc. Como tradutor da equipe, ainda que especialista no par linguístico Português-Espanhol, realizei em seguida a parte de pré-revisão ortográfica e gramatical do material. Por fim, todo o material textual foi revisado externamente por uma tradutora do par Português-Inglês, porém com uma redução importante no tempo e custo final desse serviço terceirizado.

\section{Primeiros passos de gestão interna da localização - a emergência de métodos e estratégias}

Apesar do incipiente incremento das questões de localização ao processo de tomada de decisões, Dragon Festival nos ajudou a concluir quais etapas são essenciais a serem discutidas no que tange à gestão interna de desenvolvimento de um game, além de impulsionar os coordenadores de projeto a buscarem referências de boas práticas na área, a fim de guiar ou gerenciar essa etapa com eficiência. Porém, somente esse caso ainda não havia sido suficiente para demonstrar a importância da área de tradução/localização e de sua necessidade prioritária.

\section{Segundo caso de tradução/localização: Beating Memories}

Praticamente ao final da etapa de game design de Dragon Festival, em janeiro de 2013, a Dumativa participou do evento mundial "Global Game Jam" $(\mathrm{GGJ})^{12}$, que reúne milhares de estúdios e desenvolvedores indie ao redor do mundo. Em um período de 48 horas, simultaneamente, todas as sedes ${ }^{13}$ devem produzir um jogo para ser disponibilizado no site oficial do GGJ, apenas com o objetivo lúdico de produzir um game e interagir com as demais produções do redor do mundo, sem financiamento ou disputas, e num exíguo período de tempo. Trata-se de um evento de importância no meio dos jogos independentes, revelando protótipos de jogos que eventualmente chegam ao mercado. Exemplo disso, conforme Adi Robertson apontou em 2013 no portal The Verge, foi o caso do game Surgeon Simulator, cujo protótipo foi produzido durante a GGJ 2013 pelo estúdio inglês “Bossa Studios"14, e hoje é comercializado em sua versão final na Steam ${ }^{15}$.

\footnotetext{
12 http://globalgamejam.org/

${ }^{13}$ As sedes (“jam sites”) da Global Game Jam são estúdios de desenvolvimento e polos tecnológicos que se inscrevem para participar oficialmente do evento, servindo de espaço físico para a produção de desenvolvedores internos e convidados. Segundo as informações do site oficial, em 2014 a GGJ contou com 488 sedes registradas, que “abrigaram” mais de 23 mil participantes de 72 países. (http://globalgamejam.org/news/ggj-2014-numbers)

${ }_{14}$ http://www.bossastudios.com/

${ }^{15}$ A Steam, desenvolvida pela Valve Corporation, é uma plataforma de distribuição digital que gerencia a venda, os direitos e os serviços multiplayer de jogos para PC e Mac. Em 2014, a plataforma
} 
Em cada edição (anual) há um tema diferente, revelado no início do evento, em 2013 esse foi o som do pulsar cardíaco. Após uma reunião, a equipe de game design da Dumativa decidiu desenvolver um game para PC baseado em narrativa e texto, nos moldes dos gamebooks ${ }^{16}$, no qual as escolhas do leitor-jogador resultam em consequências diretas que moldam e direcionam o enredo. $\mathrm{O}$ diferencial, que imergia no jogo a partir da temática proposta era que o jogador não controlaria o personagem principal em primeira pessoa, e sim seu coração avariado por uma arritmia.

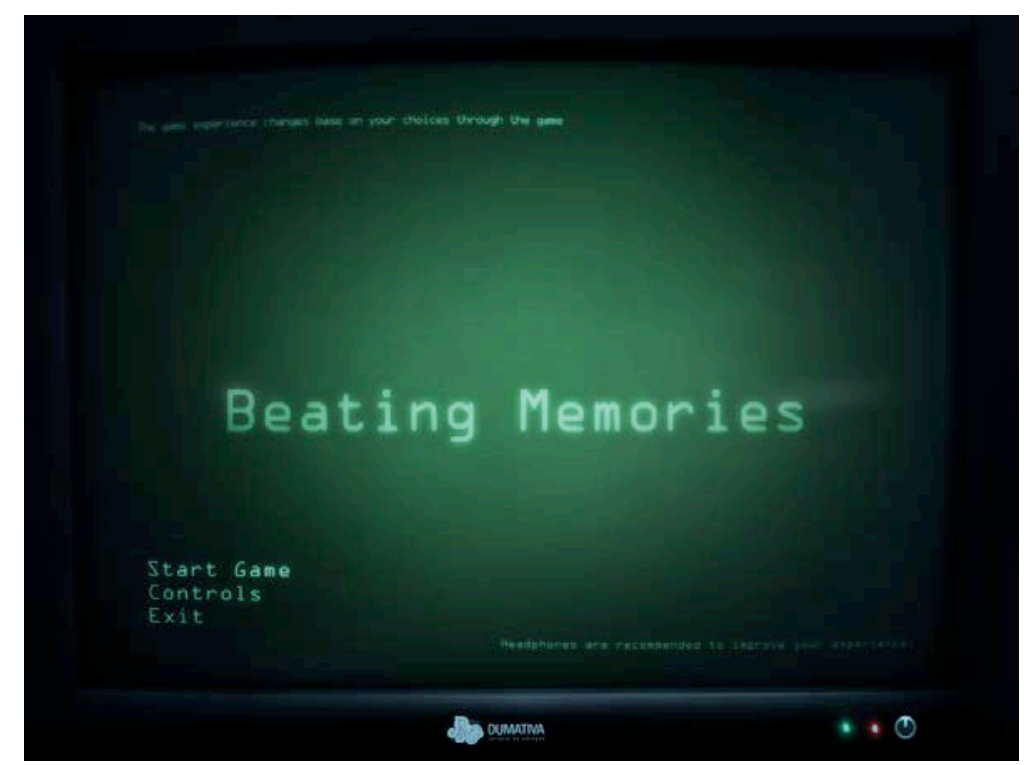

Figura 3. Tela inicial de Beating Memories ${ }^{17}$

Em seguida, já cônscios da posição da localização no ordenamento do game design, resolveu-se que o texto seria em língua inglesa, devido ao caráter internacional do evento, e isso impactaria de modo crítico no planejamento e construção da parte textual - que consiste da parte majoritária de um jogo dessa natureza.

\section{Traçando os pontos primários de tradução e localização do texto}

A partir disso, nós, da equipe de produção literária, iniciamos o planejamento, porém com questões básicas de tradução e localização que deveriam ser resolvidas antes que se começasse o processo de definição do argumento da narrativa: situá-lo no Brasil?

- Aproximar o ambiente ao leitor anglo-americano ou geograficamente

- Qual seria a natureza dos nomes dos personagens?

- Contarmos com localidades fictícias ou reais?

alcançou as marcas de 4 mil jogos digitais publicados e de mais de 75 milhões de usuários ativos registrados, segundo o portal Gamasutra e a ferramenta de busca da Steam.

${ }^{16}$ Gamebooks são livros de RPG onde o leitor-jogador realiza escolhas que modificam o decorrer da narrativa, impactando na formação do personagem principal.

${ }^{17}$ O protótipo do jogo ainda pode ser baixado na página da Global Game Jam 2013. 
Estas e outras questões formaram um guia prévio para facilitar os processos de composição e de tradução/localização, até a finalização do produto textual, tendo em vista o cronograma exageradamente curto, conforme a proposta do evento.

\section{O dilema de traduzir "sem tradutores"}

O grande obstáculo para o planejamento da narrativa e da tradução consistia no fato de que não havia na sede nenhum tradutor no par Português-Inglês, e nós da equipe de produção não possuímos proficiência em inglês o suficiente para apresentar uma narrativa literária de qualidade similar à escrita por nós em português ou espanhol. Devido ao curto prazo de produção, não seria possível terceirizar a tradução, o que nos obrigou a criar um método de três etapas como solução do problema, que incluiria a formação de uma equipe de tradutores proficientes em língua inglesa para realizar a etapa de tradução.

\section{Encaminhamento da tradução/localização na criação do texto de origem}

Embora não houvesse tradutores especialistas em língua inglesa na equipe, havia um suficiente número de integrantes que tinham boa proficiência nessa língua, o que viabilizaria a etapa de tradução, ainda que não do modo ideal. Assim, seria possível a produção do texto original em português para a posterior tradução ao inglês. Entretanto, para tal, deveríamos criar meios para que o texto exigisse o menor esforço possível da capacidade tradutória dos integrantes responsáveis por essa parte, tendo em vista que não haviam tido treinamento prévio para tal atividade.

Sendo assim, utilizamos os estudos de Heloísa Cintrão (2007) a respeito das questões de dificuldade para o aprendizado da competência tradutória para planejar nosso trabalho de composição com vistas à posterior tradução. Segundo Cintrão, elementos culturalmente marcados, funções poéticas e traduções subordinadas $^{18}$ são pontos-chave para o desenvolvimento da competência tradutória em aprendizes, o que nos levou a considerar que deveríamos evitá-los em nossa narrativa, ao menos nas partes iniciais do protótipo que seria traduzido. Desse modo, tentamos evitar ao máximo expressões conotativas, substantivos metaforizados, representações feitas por letras iniciais de palavras, efeitos e referências fonéticas, referências a expressões corporais, etc. Com isso, esperávamos limitar as dificuldades e eventuais equívocos na tradução.

\section{Orientações textuais e treinamento de pessoal proficiente}

Tendo em vista que em produção literária é difícil evitar todos os casos mencionados acima, decidimos criar um "guia" para os casos esperados de conflito. Nele detalhamos:

\footnotetext{
18 “Traduções subordinadas”, segundo descreve Carvalho (2005), são aquelas limitadas por códigos semióticos extralinguísticos, como o espaço físico destinado a ela e elementos visuais e sonoros determinantes em um contexto. A dublagem e a legendagem oferecem uma gama de exemplos desse tipo de tradução.
} 
- $\quad$ os elementos que não deveriam ser traduzidos e/ou adaptados, devendo ser mantidos na língua original;

- indicações prévias de estratégias de tradução, pensadas durante a construção da narrativa;

- $\quad$ pré-determinações de traduções para determinados termos.

Esse documento paralelo teria como função preparar o pessoal proficiente para um melhor desempenho na tradução, representando uma espécie de enxerto à competência tradutória da equipe.

\section{Foco na revisão da tradução}

Para o terceiro passo do método estipulado, foi necessário que se dividissem os textos em quantidade igualitária para cada integrante da equipe de tradução, a fim de que para cada texto traduzido sempre houvesse ao menos um integrante que não tivesse participado de sua tradução. Assim, cria-se, ficaria minimizada a ocorrência de erros de adaptação, inclusive dinamizando a etapa de revisão ortográfica.

\section{Resultados das experiências}

A localização de Dragon Festival, somada ao processo de produção e tradução de Beating Memories, resultou em pontos muito positivos para o estúdio e nossa equipe. Por meio da produção dos dois jogos, ficou clara a importância da tradução/localização frente à construção do game design, tendo criado na equipe a consciência de que não é uma fase a ser postergada, e que impacta diretamente no resultado, no cronograma e na atividade de todas as áreas envolvidas. As bases teóricas da tradução tiveram sua pertinência demonstradas na prática, o que acelerou a busca por meios de especializar a equipe na área de localização.

Ainda que nosso foco seja internalizar as atividades de desenvolvimento, a Dumativa atualmente mantém atualizado um banco de dados de profissionais freelancers de diversas áreas para atuação em projetos - e devido às experiências do último ano, a área de tradução/localização adquiriu considerável peso e independência dentro desse cadastro de profissionais.

\section{Conclusões}

Ainda que entrar e permanecer no mercado de games seja um desafio, no decorrer de nossos projetos conseguimos enxergar mais possibilidades do que limitações. Os erros e acertos durante diversas etapas de produção nos ajudaram a consolidar experiências, criar metodologias e concretizar ideias. No desenvolvimento dos dois jogos citados, assim como nos de outros projetos em andamento, não só o processo de tradução foi incorporado à prática de game design - programação, design, música, texto - como cada uma de suas áreas específicas foi aprimorada e refinada por essa incorporação, resultando em uma nítida melhora de qualidade do produto final. 
Assim, chegamos à conclusão de que um dado sistema não necessariamente se aplica a todas as realidades empresariais, mas há pontos que devem embasar quaisquer sistemas. Internalizando as atividades de tradução/localização, ou terceirizando-as, consideramos que um estúdio independente precisa possuir uma equipe de profissionais (internos e/ou externos) capacitada nas habilidades e experiências mais diretas para as fases de desenvolvimento, como a arte, a programação, a sonorização, entre outras. Assim como a produção literária é uma importante peça de uma equipe de games indie, profissionais de tradução e localização são imprescindíveis para a produção eficaz de um game - principalmente ao se pensar em um mercado como o nosso, ainda voltado para o exterior.

\author{
Jorge Luís Rocha \\ jorge@dumativa.com.br \\ Tradutor da Dumativa Estúdio de Criação / Mestrando em Letras Neolatinas \\ Universidade Federal do Rio de Janeiro
}

\title{
Referências bibliográficas
}

Carvalho, Carolina Alfaro de. A tradução para legendas: dos polissistemas à singularidade do tradutor. Dissertação de Mestrado, 2005, Rio de Janeiro. Pontifícia Universidade Católica do Rio de Janeiro (PUC-RJ). Disponível em:

<http://www.scribatraducoes.com.br/files/CarolinaAlfaroCarvalho_2005_Tr aducaoParaLegendas_Dissertacao.pdf> Acesso em: 13 novembro 2014.

CinTrão, Heloísa Pezza. Tradução subordinada, tradução poética e elementos culturalmente marcados num curso introdutório: experimento sobre a aquisição da CT. In: XII SETA - Seminário de Teses em Andamento, 2007, Campinas. Anais do SETA (UNICAMP), 2007. v. 1. p. 301-307.

ENCICLOPEDIA BRITANNICA. Shenlong. Artigo. Disponível em: <http://global.britannica.com/EBchecked/topic/539841/Shenlong>. Acesso em 30 dezembro 2013.

Global Game Jam. GGJ 2013 Live Status. Maiores locais de jam por número de registros. Disponível em: <http://2013.globalgamejam.org/status>. Acesso em 30 dezembro 2013.

Jogos eletrônicos entram na Lei Rouanet. EXAME.com, 12 dezembro 2011. Disponível em:

$<$ http://exame.abril.com.br/tecnologia/noticias/jogos-eletronicos-entram-nalei-rouanet>. Acesso em 13 novembro 2014. 
Nunes, Douglas. Mercado de games explode no Brasil. Brasil Econômico - IG, 24 dezembro 2013. Disponível em:

$<$ http://brasileconomico.ig.com.br/noticias/mercado-de-games-explode-nobrasil_137817.html>. Acesso em: 30 dezembro 2013.

Robertson, Adi. Steam approves sadistic, hilarious 'Surgeon Simulator 2013' for Greenlight. The Verge, 1 Março 2013. Disponível em:

$<$ http://www.theverge.com/2013/3/1/4043646/surgeon-simulator-2013coming-to-steam-greenlight $>$. Acesso em 30 dezembro 2013.

Steam now has over 75 million active accounts. Gamasutra, 15 janeiro 2014. Disponível em:

<http://www.gamasutra.com/view/news/208667/Steam_now_has_over_75_ million_active_accounts.php>. Acesso em 13 novembro 2014.

Steam Search. Valve Corporation. Disponível em:

$<$ http://store.steampowered.com/search/> . Acesso em 13 novembro 2014. 